\title{
Heterojen Ev Ağlarının Aralık Tip-2 Bulanık AHS ve TOPSIS Yöntemleri ile Değerlendirilmesi Araştırma Makalesi/Research Article
}

\author{
Serkan BALLI*, Ecem DİKMEN \\ Bilişim Sistemleri Mühendisliği, Muğla Sttkı Koçman Üniversitesi, Muğla, Türkiye \\ serkan@mu.edu.tr, ecemdkmn@gmail.com \\ (Geliş/Received:06.03.2020; Kabul/Accepted:15.09.2020) \\ DOI: $10.17671 /$ gazibtd.700104
}

\begin{abstract}
Özet-Son zamanlarda bilişim sektöründeki gelişmelerle birlikte, ev kullanıcılarına sunulan ağ teknolojilerinin performansları sürekli artış göstermektedir. Bu artış ile farklı özellik ve altyapıları kullanılarak sunulan ev ağlarındaki internet hizmeti gittikçe daha heterojen hale gelmektedir. Tüm ağların var olarak kabul edildiği bir ortamda, kullanıcıların ihtiyaçlarına göre en verimli ağ hizmetini kullanması karmaşık bir optimizasyon problemidir. Kullanılacak amaç doğrultusunda, kullanıcının ihtiyaç duyacağı ve tüm nitel ve nicel kriterler açısından en yararlı hizmeti sunacak erişim ağının seçilmesi, belirsizlik içeren çok kriterli bir karar verme problemidir. Bu çalı̧̧mada, bu belirsizliği daha iyi modelleyebilmek için aralık tip-2 bulanık AHS ve aralık tip-2 bulanık TOPSIS yöntemleri ayrı ayrı kullanılmış ve kıyaslanmıștır. Çalıșmada kullanılan kriterler; gecikme, paket kaybı, seğirme, maliyet, toplam bant genişliği ve kullanılabilir bant genişliği olarak belirlenmiștir. Daha sonra ADSL, FiberNet, Kablonet, PLC ve 3G olmak üzere beş farklı ağ, bu kriterlere göre değerlendirilmiştir. Tip-2 bulanık kümeler kullanılarak AHS ve TOPSIS yöntemlerinin uygulanması ile başarılı sonuçlar elde edilmiş ve alternatiflerin daha net ayrışması sağlanmıştır.
\end{abstract}

\section{Evaluation of Heterogeneous House Networks with Interval Type-2 Fuzzy AHP and TOPSIS Methods}

\begin{abstract}
With the recent developments in the IT sector, the performance of network technologies offered to home users has been continuously increasing. With this increase, internet services in home networks that are presented using different features and infrastructures are becoming more heterogeneous. In an environment where all networks are considered to be available, using the most efficient network service according to the needs of users is a complex optimization problem. The selection of an access network that will provide the most useful service in terms of the purpose to be used and which will be needed in terms of all qualitative and quantitative criteria is a multi-criteria decision making problem with uncertainty. In this study, in order to better model this uncertainty, interval type- 2 fuzzy AHP and interval type- 2 fuzzy TOPSIS methods are used separately and compared. Criteria used in the study; delay, packet loss, jitter, cost, total bandwidth, and available bandwidth. Then, five different networks, ADSL, FiberNet, Cable network, PLC and 3G, are evaluated according to these criteria. Successful results are obtained with the application of AHS and TOPSIS methods by using Type- 2 fuzzy sets and a clearer separation of the alternatives is achieved.
\end{abstract}

Keywords-Interval Type-2 fuzzy set, Fuzzy Logic, TOPSIS, Analytic hierarchy process, Heterogeneous network selection 


\section{GİRISŞ (INTRODUCTION)}

Dünyada ve ülkemizdeki teknolojik gelişmelerin ilerlemesi ile birlikte internet hattı abone sayısı gittikçe artmaktadır. Gelişen teknoloji ile birlikte abonelerin, kullandıkları internet teknolojileri hakkında ayrıntılı bilgi sahibi olmaları mümkün değildir. Her ağın kendine özel servis kalitesi ve özellikleri olduğu gibi kullanıcıların da benzer şekilde kendi ihtiyaçlarına yönelik en verimli ağı seçmesini sağlamak karmaşık bir problemdir. Kullanıcılar böyle bir problemle karşılaştı̆̆ında genellikle bilgi eksikliğinden dolayı yanlış karar vermekte, sadece maliyet ve toplam bant genişliği gibi değerlere bakarak seçim yapmaktadırlar. Oysa ağdaki gecikme ve kullanılabilir bant genişliği vb. kriterler de ağın kalitesi hakkında öneme sahiptir. Böyle bir problemde tek kriter ile seçim yapmak, verimli sonuca ulaşmak için yetersizdir. Yanlış bir ağ seçimi maliyet ve hizmet açısından kötü bir deneyime sebep olabilir [1]. Hızla gelişen teknolojiler içerisinde kullanıcı için en verimli ağın seçilmesi probleminde yer alan sözel değerlendirmelerdeki belirsizlikler, karar vermeyi oldukça zorlaştırmaktadır. Bu çalışmada, belirsiz kriterler için bulanık mantık kullanılmıştır. Bulanık mantık kavramına, klasik mantığın gerçek dünyada yeterli olmadığı problemlerde ihtiyaç duyulmaktadır [2]. Örneğin hava sıcak ya da aşırı sıcak olabilir. Aşırı sıcak havanın matematiksel olarak kümesini tanımlamak oldukça zordur ve böyle bir durumda klasik mantık kuramının tüm problemleri modelleyemediği görülür. Bulanık küme kuramı, belirsizlik içeren bu tür problemleri çözmek için geliştirilmiştir [3]. Dilsel ifadeleri sayısal olarak derecelendirerek ifadelerden anlam ve sonuç çıkarabilme imkânı sağlamaktadır [4]. Bulanık kümeleri tanımlayan üyelik fonksiyonları Tip-1 ve Tip-2 olarak iki grupta incelenebilir. Tip-1 bulanık kümelerin üyelik fonksiyonları $[0,1]$ kapalı aralığında ifade edilen bir küme olarak tanımlanır. Üyelik derecesini $[0,1]$ aralığında tanımlamada hala belirsizlik yaşanıyorsa Tip-2 bulanık kümeler kullanılır. Ek olarak belirsizliğin değeri net olarak bilinemiyorsa Tip-1 yerine Tip-2 bulanık kümeleri tercih etmek daha doğru sonuçlar ortaya çıkarmaktadır. Belirsizliklerin temel sebepleri; uygulamada tanımlanacak olan kelimelerin anlamlarının farklı kişilere göre farklı anlamlandırılabilmesi, uzman görüşlerinin farklı fikirlere sahip uzmanlardan elde edilebilmesi veya kullanılan verilerin gürültülü olabilmesidir. Şekil 1 (a)'da L isimli bir bulanık küme için üyelik fonksiyonu verilmiştir [5]. Bu kümede her üye için kendine ait kesin üyelik derecesi değeri vardır. Başka bir deyişle, belirsizliği net olarak modelleyememesinin sebebi, üyelik fonksiyonun keskin sınırları olmasından kaynaklanmaktadır. Tip-2 bulanık kümelerde üyelik fonksiyonları Şekil 1 (b)'de gösterildiği gibi üç boyutlu olarak tanımlanmaktadır [6]. Tip-2 bulanık küme, $\tilde{L}$ olarak gösterilir. Ayrıca, bulanık kümedeki her üye artık keskin bir değere değil, bunun yerine bir aralığa sahiptir. Böylece belirsizlikler Tip-2 bulanık kümelerle daha iyi modellenebilmektedir. Şekil 1 (b)'de Tip-2 bulanık küme $\bar{L}$ ve $\underline{L}$ olarak adlandırılan üst ve alt tip-1 kümelerle sinırlandırılır. $\bar{L}$ ve $\underline{L}$ arasındaki kalan alana ise belirsizliğin kapladığı alan (FOU-Footprint Of Uncertainty) denir [5].

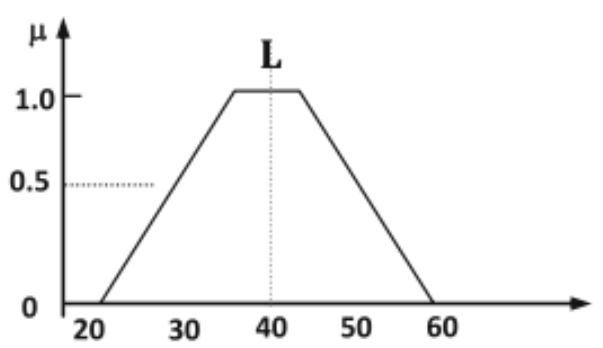

(a)

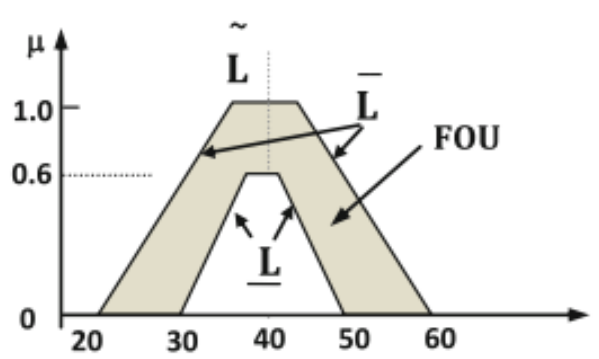

(b)

Şekil 1: (a) Tip-1 bulanık küme, (b) Tip-2 bulanık küme [5] (Type-1 fuzzy set, Type-2 fuzzy set)

$\mathrm{Bu}$ çalışmada, ev kullanıcılarına sunulan ağ teknolojilerinin performanslarını değerlendirmek için Tip2 bulanık kümelerden faydalanılarak bir karar verme sistemi geliştirilmiştir. Literatür incelendiğinde en verimli ağ hizmetini sunacak erişim ağının seçilmesi ile ilgili örnekler aşağıdaki gibi sıralanabilir:

Wang vd. [7] heterojen kablosuz ağlar için kural tabanlı bir seçim sistemi geliştirmiştir. Alexandri vd. [8] multimedya kablosuz sistemlerde erişim ağı seçimi için çalışma sunmuşlardır. Wang ve Binet [9] heterojen kablosuz ağlarda çok kriterleri karar verme tabanlı bir çalışma ile ağ seçim modeli üzerine çalışmışlardır. Macriga ve Kumar
[10] özellikle hizmet kalitesinin ele alındığı heterojen kablosuz ağlarda kesintisiz bilgi akışı için ağ seçim yaklaşımı önermişlerdir. TalebiFard ve Leung [11], TOPSIS ve WPM yöntemleri kullanılarak heterojen bilgisayar ağlarında en verimli ağ seçimi için bir model önermişlerdir. Tüker [12] yaptığı çalışmada heterojen bilgisayar ağları için bulanık Tip-1 TOPSIS ve AHS yöntemlerini kullanarak zeki bir seçim sistemi geliştirmiştir. Koçak ve Çoğurcu [13] tarafından yapılan çalışmada network modeli ile ağ performanslarının değerlendirilmesi için çok kriterli karar verme yöntemlerinden bulanık TOPSIS ve bulanık VIKOR yöntemleri kullanılmıştır. Drissi vd. [14] heterojen 
kablosuz ağlarda ağ seçiminin geliştirilmesine bir bulanık AHS yaklaşımı önermişlerdir. Sasirekha vd. [15] heterojen kablosuz ağlarda el değiştirme işlemi için melez bir çok kriterli karar verme tekniği kullanarak bir model önermişlerdir. Kunarak ve Sulessathira [16] heterojen mobil IP ağları için çok kriterli dikey devir karar algoritması geliştirmişlerdir. Kumar ve Gupta [17] heterojen radyo ağları için kullanıcı tercihleri ile çok kriterli karar verme kullanarak ă̆ seçimi yapmışlardır.

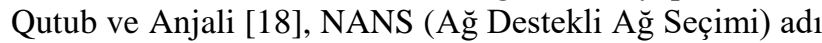
verilen bir model sunmuşlardır. Sunulan modelde kullanıcı ihtiyaçları doğrultusunda ă̆ kaynaklarının durumları da göz önünde bulundurularak ağ seçimi için AHS metodu kullanılmıştır. Ballı ve Tüker [19] Türkiye'de ağ hizmet sağlayıcılarının değerlendirilmesinde dört farklı profil ve altı farklı kriter kullanarak ağ seçimi için Tip-1 küme kullanan bir bulanık çok kriterli karar analizi yaklaşımı sunmuşlardır.

Verilen literatüre bakıldığında, heterojen bilgisayar ağlarının seçimi için bulanık mantık tabanlı çok kriterli karar verme yöntemlerinin sıklıkla kullanıldığ görülmektedir. Çalışmaların genel çoğunluğunda, Tip-1 bulanık kümeler kullanılarak değerlendirmeler yapılmıştır. Bu çalışmada geçmiş çalışmalardan farklı olarak, heterojen ev ağlarının değerlendirilmesinde aralık tip-2 bulanık kümeler kullanılarak belirsizliğin daha iyi modellenmesi amaçlanmıştır. Çalışma kapsamında kullanıcı için en uygun ağın seçimi ele alınmıştır. Aralık Tip-2 bulanık küme kullanımı ile konu bazında daha önce bir araya getirilmemiş olan aralık tip-2 bulanık AHS ve aralık tip-2 bulanık TOPSIS yöntemleri ayrı ayrı kullanılarak bir karar destek sistemi oluşturulmuştur.

$\mathrm{Bu}$ çalışmada, Tüker [12] çalışmasındaki veriler doğrultusunda belirlenen kriterler ve alternatifler ile kullanıcının gereksinimi dikkate alınarak, aday ağların değerlendirilmesi için çok kriterli karar verme yöntemlerinden olan Aralık Tip-2 Bulanık AHS (Analitik Hiyerarşi Süreci) ve Aralık Tip-2 TOPSIS yöntemleri ile seçme işlemi yapılmaktadır. Kullanıcının bulunduğu ortamda tüm alternatiflerin teknolojik altyapılarının var olduğu kabul edilmiştir. Belirlenen kriterler ve alternatifler doğrultusunda karar vericiler yardımı ile Aralık Tip-2 kümelere göre değerlendirme yapılmıştır. Değerlendirilecek olan ev kullanıcıları için hizmete sunulan kablolu heterojen ağlar; ADSL (Asymmetric Digital Subscriber Line), FiberNet (Fiber İnternet), Enerji hattı üzerinden internet (PLC-Powerline Communication), ve Kablonet (Kablo İnternet) teknolojileri olarak belirlenmiştir. Kablosuz olarak ise Hücresel-3G (3rd Generation), servis sağlayıcılarının kullanıcılara sunduğu mobil iletişim teknoloji seçilmiştir. Çalışmada kullanılan kriterler ise; gecikme, paket kaybı, seğirme, maliyet, toplam bant genişliği ve kullanılabilir bant genişliği olarak belirlenmiştir.

Çalışmanın ikinci bölümünde kullanılan materyal ve metotlar hakkında bilgi verilmiştir. Üçüncü bölümde ağ seçimi için kullanılan Aralık Tip-2 AHS ve TOPSIS yöntemlerinin uygulaması ele alınmıştır. Son bölümde ise çalışmanın sonuçları tartışılmıştır.

\section{MATERTAL VE METOT (MATERIAL AND METHOD)}

\subsection{Heterojen ev ăgları ve performansını etkileyen parametreler (Heterogeneous home networks and parameters affecting their performance)}

Kablolu ve kablosuz olarak siniflandirılan heterojen bilgisayar ağları, bu çalışmada ev kullanıcıları için ADSL, Fiber İnternet, PLC, Kablonet ve 3G sistemleri olarak belirlenmiştir.

ADSL, Türkiye'de 2019 yılı itibari ile internet bağlantısı için en çok kullanılan kablolu bağlantı tekniğidir [20]. Bir ayırıcı (splitter) yardımı ile telefon ve veri hattı eşzamanlı olarak kullanılabilir. Veri transfer hızı gönderim ve alım için eşit değildir [21]. Fiber İnternet, fiber optik kablolar ile gerçekleştirilen geniş bant sağlayan diğer bir kablolu teknolojidir. [22] Veri kaybı çok azdır ve 1şık hızında bağlantı sağlar. PLC (Powerline Communication) ise yeni kablolara ihtiyaç duymadan enerji hattı üzerinden veri taşıma amaçlı kullanılan bir sistemdir. Veri, enerji hattı üzerinde bulunan gürültü ve zayıflama etkileri nedeniyle yüksek kalitede iletişimi engellemektedir [23]. Kablonet, Kablo TV altyapısını kullanarak geniş bant ağ teknolojisi sunan bir teknolojidir. ADSL'in aksine, simetrik bağlantı seçeneği de mevcuttur [24]. Kablosuz ağ teknolojisi olan $3 \mathrm{G}$ ise, mobil servis sağlayıcılarının sunduğu veri ve yüksek hızda internet bağlantısı sağlayan üçüncü nesil bir teknolojidir. Bant genişliği sınırlıdır ve internet kullanımı bayt başına düşen maliyeti artırmaktadır [25].

Heterojen ev ağları, sadece altyapılarına göre değil sundukları parametrelere göre de farklılık göstermektedirler. Bu çalışmada kullanılan parametreler; toplam bant genişliği, kullanılabilir bant genişliği, gecikme, seğirme, paket kaybı, maliyet olarak ele alınmaktadir.

Toplam Bant Genişliği (TBG): Bir hat ya da ağ üzerinden saniyede iletilebilen maksimum bit sayısı olarak tanımlanır [26].

Kullanılabilir Bant Genişliği (KBG): Var olan ağın gerçek zamanlı uygulamalar sırasında sunduğu bant genişliği olarak adlandırılır [27].

Gecikme (G): Bir bilgi paketinin kaynaktan hedefe gidene kadar geçen zaman değeridir [26].

Seğirme (S): Bir sinyalin normalde olması gereken değere göre hatalı değer vermesidir. İletilen bit dizilerinin zamanlama ve büyüklüklerindeki sapmaları ifade eden seğirmenin yüksek değerlere ulaşması paketlerin kaybolmasına ya da yeniden gönderilmesine sebep olabilir.

Paket Kaybı (PK): Kaynaktan ayrilan paketin hedefe ulaşamadan kaybedilmesi ya da paketin ulaştığı hedefteki 
hafiza kısıtlarından dolayı kabul edilememesi olarak tanımlanmaktadır [27].

Maliyet (M): Her servis sağlayıcısının sunduğu hizmet için belirlediği ücret olarak ele alınmaktadır.

\subsection{Aralık Tip-2 Bulanık AHS Yöntemi (Interval Type-2 Fuzzy AHP method)}

Aralık Tip-2 AHS yöntemi, karar verme kriterlerini bir hiyerarşi olarak organize eder ve karar vericilerin çift yönlü kararlarına dayanarak belirli bir alternatifler kümesi için göreceli öncelikleri belirlemeyi amaçlar. Çalışmada, Buckley'nin Tip-1 bulanık AHS yöntemi [28, 33], aralık Tip-2 bulanık kümeleri kullanılarak uygulanmıştır.

Aralık Tip-2 bulanık kümeler aşağıdaki gibi tanımlanmaktadır:

$\tilde{\tilde{\mathrm{A}}}_{1}=\left(\tilde{\mathrm{A}}_{1}^{U}, \tilde{\mathrm{A}}_{1}^{L}\right)=\left(\left(a_{11}^{U}, a_{12}^{U}, a_{13}^{U}, a_{14}^{U} ; \mathrm{H}_{1}\left(\tilde{\mathrm{A}}_{1}^{U}\right), \mathrm{H}_{2}\left(\tilde{\mathrm{A}}_{1}^{U}\right)\right)\right.$, $\left(a_{11}^{L}, a_{12}^{L}, a_{13}^{L}, a_{14}^{L}: H_{1}\left(\tilde{\mathrm{A}}_{1}^{L}\right), \mathrm{H}_{2}\left(\tilde{\mathrm{A}}_{1}^{L}\right)\right)$

$\tilde{\tilde{\mathrm{A}}}_{2}=\left(\tilde{\mathrm{A}}_{2}^{U}, \tilde{\mathrm{A}}_{2}^{L}\right)=\left(\left(a_{21}^{U}, a_{22}^{U}, a_{23}^{U}, a_{24}^{U} ; \mathrm{H}_{1}\left(\tilde{\mathrm{A}}_{2}^{U}\right), \mathrm{H}_{2}\left(\tilde{\mathrm{A}}_{2}^{U}\right)\right)\right.$, $\left(a_{21}^{L}, a_{22}^{L}, a_{23}^{L}, a_{24}^{L}: H_{1}\left(\tilde{\mathrm{A}}_{2}^{L}\right), \mathrm{H}_{2}\left(\tilde{\mathrm{A}}_{2}^{L}\right)\right)$

Yöntemin adımları aşağıdaki gibidir [29]:

Adım 1: Kriterler arasında ikili karşılaştırma matrisleri oluşturulur.

$$
\begin{aligned}
& \left(\begin{array}{ccc}
1 & \ldots & \tilde{\tilde{a}}_{1 n} \\
\vdots & \ddots & \vdots \\
\tilde{\tilde{a}}_{n 1} & \ldots & 1
\end{array}\right)=\left(\begin{array}{ccc}
1 & \ldots & \tilde{\tilde{a}}_{1 n} \\
\vdots & \ddots & \vdots \\
1 / \tilde{\tilde{a}}_{n 1} & \ldots & 1
\end{array}\right) \\
& 1 / \tilde{a}=\left(\left(\frac{1}{a_{14}^{U}}, \frac{1}{a_{13}^{U}}, \frac{1}{a_{12}^{U}}, \frac{1}{a_{11}^{U}} ; \mathrm{H}_{1}\left(\mathrm{a}_{12}^{U}\right), \mathrm{H}_{2}\left(\mathrm{a}^{U}{ }_{13}\right)\right)\right),\left(\frac{1}{a_{24}^{L}}, \frac{1}{a_{23}^{L}}, \frac{1}{a_{22}^{L}}, \frac{1}{a_{21}^{L}} ; \mathrm{H}_{1}\left(\mathrm{a}^{U}{ }_{22}\right), \mathrm{H}_{2}\left(\mathrm{a}^{U}{ }_{23}\right)\right)
\end{aligned}
$$

Adım 2: Oluşacak bulanık ikili karşılaştırma matrisinin tutarlılığ incelenir. Bulanık ikili karşılaştırma matrislerinin tutarlılığını kontrol etmek için DTriT veya DTraT yaklaşımı kullanılır [29].

Adım 3: Eşitlik 2 ve eşitlik 3 kullanılarak her satırın geometrik ortalaması hesaplanır ve daha sonra bulanık değerler normalleştirilir.

$$
\begin{gathered}
\tilde{\tilde{r}}_{i}=\left[\tilde{\tilde{a}}_{i 1} \otimes \ldots \otimes \tilde{\tilde{a}}_{i n}\right]^{1 / n} \\
\sqrt[n]{\tilde{\tilde{a}}_{i j}}=\left(\begin{array}{l}
\left(\sqrt[n]{a_{i j 1}^{U}}, \sqrt[n]{a_{i j 2}^{U}}, \sqrt[n]{a_{i j 3}^{U}}, \sqrt[n]{a_{i j 4}^{U}} ; H_{1}^{u}\left(a_{i j}\right), H_{2}^{u}\left(a_{i j}\right)\right) \\
\left.,\left(\sqrt[n]{a_{i j 1}^{L}}, \sqrt[n]{a_{i j 2}^{L}}, \sqrt[n]{a_{i j 3}^{L}}, \sqrt[n]{a_{i j 4}^{L}} ; H_{1}^{L}\left(a_{i j}\right), H_{2}^{L}\left(a_{i j}\right)\right)\right)
\end{array}\right)(3)
\end{gathered}
$$

Kriterlerin ağırlığg aşağıdaki gibi hesaplanır;

$$
\tilde{\tilde{w}}=\tilde{\tilde{r}} \otimes\left[\tilde{\tilde{r}} \otimes \ldots \otimes \tilde{\tilde{r}} \otimes \ldots \tilde{\tilde{r}}_{n}\right]^{-1}
$$

Adım 4: Bulanık ağırlıklar kullanılarak kriterlerin öncelikli ağırlıkları hesaplanır:

$$
\tilde{U}_{\hat{\imath}}=\sum_{j=1}^{n} \tilde{\tilde{w}}_{j} \tilde{\tilde{r}}_{i j}, \forall i .
$$

Adım 5: En iyi alternatifi belirlemek için klasik AHS yönteminin prosedürü uygulanır. Alternatiflerin sıralarını belirlemek için Aralık Tip-2 bulanık sayılar durulaştırılır ve en büyük değer en iyi alternatif olarak seçilir.

2.3. Aralık tip-2 bulanık TOPSIS yöntemi (Interval Type-2 Fuzzy TOPSIS method)

TOPSIS, pozitif ideal çözüme en yakın ve negatif ideal çözüme en uzak mesafeye göre alternatifi seçen çok kriterli bir karar verme yöntemidir [30, 31]. 2010 y1lında Chen ve Lee'nin yapmış oldukları çalışmada [32] var olan TOPSIS yöntemi aralık Tip-2 bulanık kümeler ile genişletilerek çok kriterli karar verme yöntemlerini çözmek için yeni bir model oluşturulmuştur. $\mathrm{Bu}$ modele göre uygulanacak adımlar aşağıdaki gibidir:

Adım 1: p. karar verici için $Y_{p}$ karar matrisi ve $\bar{Y}$ ortalama karar matrisi oluşturulur.

$$
\begin{aligned}
& \mathrm{x} 1 \quad \mathrm{x} 2 \ldots \mathrm{xn}
\end{aligned}
$$

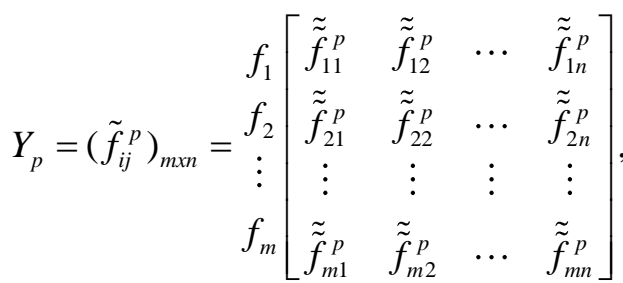

$$
\begin{aligned}
& \bar{Y}=\left(\tilde{f}_{i j}\right)_{m x n}
\end{aligned}
$$

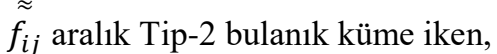

$$
\tilde{\tilde{f}}_{i j}=\left(\frac{\tilde{\tilde{f}}_{i j}^{1} \oplus \tilde{\tilde{f}}_{i j}^{2} \oplus \ldots \oplus \tilde{\tilde{f}}_{i j}^{k}}{k}\right)
$$

$1 \leq i \leq m, 1 \leq j \leq n, 1 \leq p \leq k$ olmak üzere, $\mathrm{k}$ karar verici sayısını gösterir.

Adım 2: Karar vericinin niteliklerinin $W_{p}$ ağırlık matrisi ve $\bar{W}$ ortalama ağırlık matrisi oluşturulur.

$$
W_{p}=\left(\tilde{\tilde{w}}_{i}^{p}\right)_{1 x m}=\left[\begin{array}{cccc}
\tilde{\tilde{w}}_{1}^{p} & \tilde{\tilde{w}}_{2}^{p} & \cdots & \tilde{\tilde{w}}_{m}^{p}
\end{array}\right],
$$

$$
\bar{W}=\left(\tilde{\widetilde{w}}_{i}\right)_{1 x m}
$$


$\widetilde{\widetilde{w}}_{i}$ aralık tip-2 bulanık küme iken,

$$
\tilde{w}_{i}=\left(\frac{\tilde{\tilde{w}}_{i}^{1} \oplus \tilde{\tilde{w}}_{i}^{2} \oplus \ldots \oplus \tilde{\tilde{w}}_{i}^{k}}{k}\right)
$$

$$
1 \leq i \leq m, 1 \leq p \leq k
$$

$\mathrm{k}$ karar verici sayısını gösterir.

Adım 3: Ağırlıklandırılmış karar matrisi $\bar{Y}_{w}$ oluşturulur:

$$
\begin{aligned}
& \begin{array}{llll}
\mathrm{x} 1 & \mathrm{x} 2 & \ldots & \mathrm{xn}
\end{array}
\end{aligned}
$$

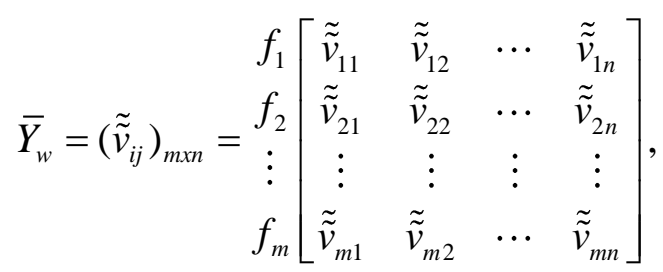

$$
\tilde{\tilde{v}}_{i j}=\tilde{\tilde{w}}_{i} \otimes \tilde{\tilde{f}}_{i j}, 1 \leq i \leq m, 1 \leq j \leq n
$$

Adım 4: Aralık Tip-2 küme olan $\tilde{\tilde{v}}_{i j}$ 'nin Rank (sıralama değeri) ( $\left.\tilde{\tilde{v}}_{i j}\right)$ değeri, eşitlik 13'e göre hesaplanır ve sıralı ağırlıklandırılmış karar matrisi $\bar{Y}^{*}{ }_{w}$ oluşturulur.

$$
\begin{aligned}
& \operatorname{Rank}\left(\tilde{\tilde{\mathrm{A}}}_{i}\right)=M_{1}\left(\tilde{\mathrm{A}}_{i}^{U}\right)+M_{1}\left(\tilde{\mathrm{A}}_{i}^{L}\right)+M_{2}\left(\tilde{\mathrm{A}}_{i}^{U}\right)+M_{2}\left(\tilde{\mathrm{A}}_{i}^{L}\right) \\
& +M_{3}\left(\tilde{\mathrm{A}}_{i}^{U}\right)+M_{3}\left(\tilde{\mathrm{A}}_{i}^{L}\right)-\frac{1}{4}\left(S_{1}\left(\tilde{\mathrm{A}}_{i}^{U}\right)+S_{1}\left(\tilde{\mathrm{A}}_{i}^{L}\right)+\left(S_{2}\left(\tilde{\mathrm{A}}_{i}^{U}\right)\right.\right. \\
& +S_{2}\left(\tilde{\mathrm{A}}_{i}^{L}\right)+\left(S_{3}\left(\tilde{\mathrm{A}}_{i}^{U}\right)+S_{3}\left(\tilde{\mathrm{A}}_{i}^{L}\right)+\mathrm{S}_{4}\left(\tilde{\mathrm{A}}_{i}^{U}\right)+S_{4}\left(\tilde{\mathrm{A}}_{i}^{L}\right)\right) \\
& +H_{1}\left(\tilde{\mathrm{A}}_{i}^{U}\right)+H_{1}\left(\tilde{\mathrm{A}}_{i}^{L}\right)+H_{2}\left(\tilde{\mathrm{A}}_{i}^{U}\right)+H_{2}\left(\tilde{\mathrm{A}}_{i}^{L}\right) \\
& \bar{Y}_{w}^{*}=\left(\operatorname{Rank}\left(\tilde{\tilde{v}}_{i j}\right)\right)_{m x n,}(1 \leq i \leq m, 1 \leq j \leq n)
\end{aligned}
$$

Adım 5: Pozitif ideal çözüm $x^{+}=\left(v_{1}^{+}, v_{2}^{+}, \ldots v_{m}^{+}\right)$ve negatif ideal çözüm $x^{-}=\left(v_{1}^{-}, v_{2}^{-}, \ldots v_{m}^{-}\right)$belirlenir.

$$
\begin{gathered}
1 \leq i \leq m, \\
v^{+}=\left\{\begin{array}{c}
\max \left\{\operatorname{Rank}\left(\tilde{\tilde{v}}_{i j}\right)\right\}, i \leq j \leq n, f_{i} \in F_{1} \\
\min \left\{\operatorname{Rank}\left(\tilde{\tilde{v}}_{i j}\right)\right\}, i \leq j \leq n, f_{i} \in F_{2}
\end{array}\right\} \\
v^{-}=\left\{\begin{array}{c}
\min \left\{\operatorname{Rank}\left(\tilde{\tilde{v}}_{i j}\right)\right\}, i \leq j \leq n, f_{i} \in F_{1} \\
\max \left\{\operatorname{Rank}\left(\tilde{\tilde{v}}_{i j}\right)\right\}, i \leq j \leq n, f_{i} \in F_{2}
\end{array}\right\}
\end{gathered}
$$

Fayda kriterlerinin kümesi $\mathrm{F}_{1}$, maliyet kriterleri kümesi $\mathrm{F}_{2}$ olarak tanımlanmıştır.
Adım 6: Her alternatif $x_{j}$ ile pozitif ideal çözüm $x^{+}$ arasındaki uzaklık d $\mathrm{d}^{+}\left(\mathrm{x}_{\mathrm{j}}\right)$ eşitlik 16'daki gibi hesaplanır.

$$
d^{+}\left(x_{j}\right)=\sqrt{\sum_{i=1}^{m}\left(\operatorname{Rank}\left(\tilde{\tilde{v}}_{i j}\right)-v_{i}^{+}\right)^{2}}, \quad 1 \leq j \leq n
$$

Her alternatif $\left(\mathrm{x}_{\mathrm{j}}\right)$ ile negatif ideal çözüm arasındaki uzaklık eşitlik 17 'deki gibi hesaplanır.

$$
d^{-}\left(x_{j}\right)=\sqrt{\sum_{i=1}^{m}\left(\operatorname{Rank}\left(\tilde{\tilde{v}}_{i j}\right)-v_{i}^{-}\right)^{2}}, \quad 1 \leq j \leq n
$$

Adım 7: $x_{j}{ }^{\prime}$ nin yakınlık katsayısı eşitlik 18'deki gibi hesaplanır:

$$
C\left(x_{j}\right)=\frac{d^{-}\left(x_{j}\right)}{d^{+}\left(x_{j}\right)+d^{-}\left(x_{j}\right)}, 1 \leq j \leq n
$$

Adım 8: $\mathrm{C}\left(\mathrm{x}_{\mathrm{j}}\right)$ değerleri büyükten küçüğe doğru sıralanır. $\mathrm{C}\left(\mathrm{x}_{\mathrm{j}}\right)$ değeri ne kadar büyükse o alternatifin seçilme tercihi o kadar yüksektir.

\section{BULGULAR (RESULTS)}

Kullanıcının ihtiyaç duyacağı ve tüm nitel ve nicel kriterler açısından en yararlı hizmeti sunacak erişim ağının seçilmesi probleminin hiyerarşik yapısı Şekil 2'de gösterilmektedir. Buna göre seçilen aday ağlar; ADSL, FiberNet, PLC, Kablonet ve Hücresel-3G servisidir. Bu ağlar değerlendirme işlemlerinde aşağıdaki isimlendirmelerle kullanılacaktır:

- $\quad \mathrm{AG} 1: 3 \mathrm{G}$

- AĞ2: ADSL

- AĞ3: FiberNet

- AĞ4: Kablonet

- AĞ5: PLC

Aday ağların değerlendirilmesi için kullanılacak kriterler ise; gecikme, paket kayb1, seğirme, maliyet, toplam bant genişliği ve kullanılabilir bant genişliği olarak belirlenmiştir.

Daha sonra aday ağlar, belirlenen kriterler ile Aralık Tip-2 Bulanık AHS ve Aralık Tip-2 Bulanık TOPSIS yöntemleri ile ayrı ayrı değerIendirilmiştir. Aşağıdaki alt bölümlerde bu yöntemlerin nasıl uygulandığından bahsedilmiştir. 


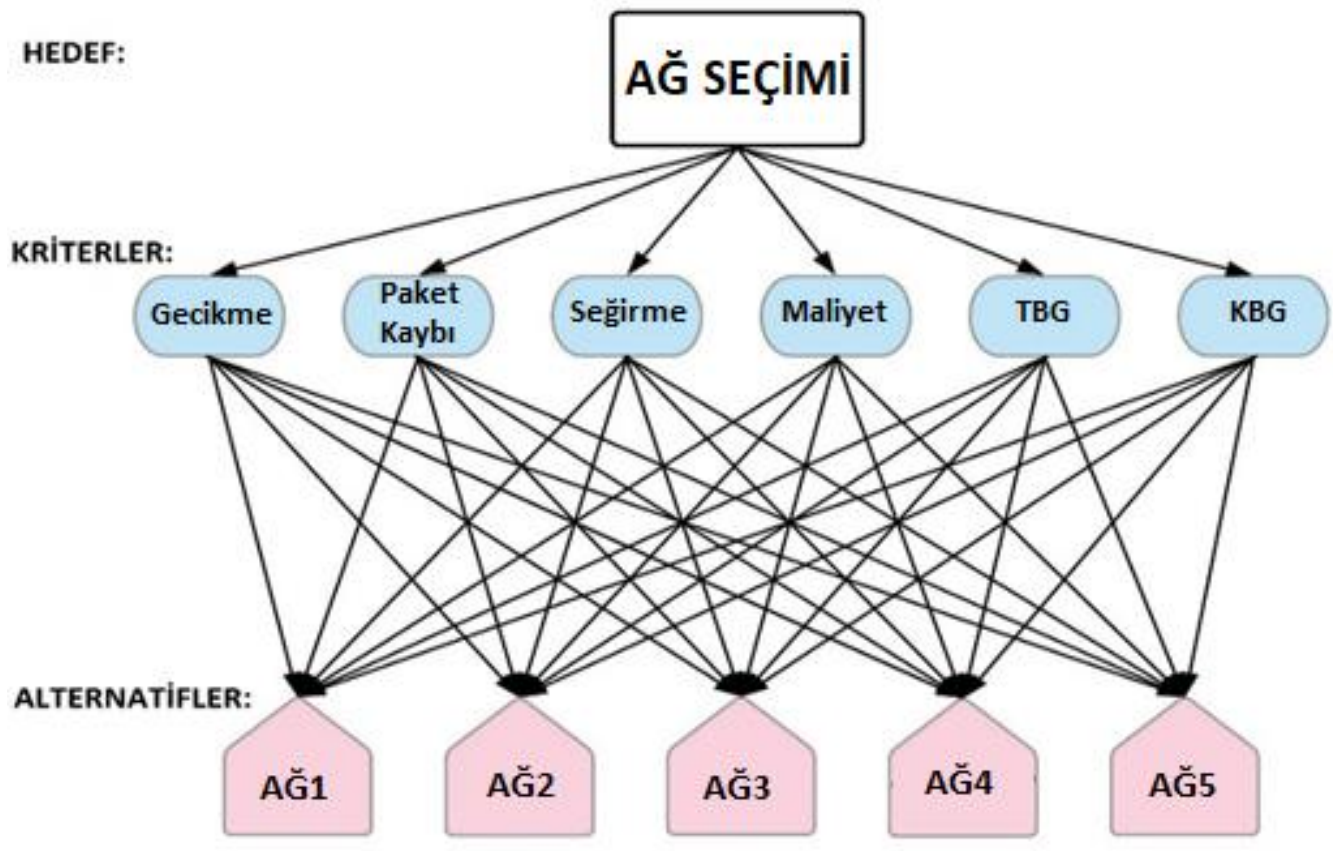

Şekil 2: Problemin Hiyerarşik Şeması

(Hierarchical Scheme of the Problem)

3.1. Aralık tip-2 bulanı AHS yöntemi ile değerlendirme (Evaluation with Interval Type-2 Fuzzy AHP method)

Aralık Tip-2 AHS yöntemine göre ilk adım olarak kriterlerin ikili karşılaştırma bulanık matrisi dilsel değerler kullanılarak oluşturulmuştur. Aralık Tip-2 kümeler için kullanılan yamuksal bulanık değerler ve buna karşılık gelen dilsel değerler Tablo 1'de belirtilmiştir. Kriterlerin çift yönlü karşılaştırma matris değerleri Tüker [12] çalışmasından alınarak Tablo 2'de gösterilmektedir. Tablo 2'nin simetriği alınmakta olup değerlerin başındaki ' $T$ ' ifadesi ters kelimesini temsil etmektedir. Dilsel değerlerin tersi Tablo 1'deki Eşit Önemli (EÖ) dilsel değerin tersi alındığında değişmediği için Tablo 2'de simetrik kısımlarda herhangi bir değişiklik yapılmamıștır. Tablo 2'de yer alan ilk satıra göre gecikme parametresi, paket kaybına göre yüksek önemli, seğirme parametresine göre eşit önemli, maliyet parametresine göre az önemli, toplam bant genişliği parametresine göre yüksek önemli, kullanılabilir bant genişliği parametresine göre ise az önemlidir. Diğer satırlar da benzer şekilde okunabilir.

Tablo 1: Dilsel değerler ve bulanık karşılıkları [28].

\begin{tabular}{|c|c|}
\hline \multicolumn{2}{|c|}{ (Linguistic values and their fuzzy equivalents) } \\
\hline $\begin{array}{c}\text { Dilsel Değerler } \\
\text { Mutlak Önemli } \\
\text { (MÖ) }\end{array}$ & $((7,8,9,9 ; 1,1)(7.2,8.2,8.8,9 ; 0.8,0.8))$ \\
\hline \begin{tabular}{c} 
Çok Önemli (ÇÖ) \\
\hline $\begin{array}{c}\text { Yüksek Önemli } \\
\text { (YÖ) }\end{array}$
\end{tabular} & $((5,6,8,9 ; 1,1)(5.2,6.2,7.8,8.8 ; 0.8,0.8))$ \\
\hline $\begin{array}{c}\text { Az Önemli (AÖ) } \\
\text { Eşit Önemli (EÖ) }\end{array}$ & $(((1,2,4,5 ; 1,1)(1.2,2.2,3.8,4.8 ; 0 ; 1,1)(3.2,4,0.2,5))$ \\
\hline
\end{tabular}

Tablo 2: Kriterlerin ikili karşılaştırılması [12]. (Pairwise comparison of criteria)

\begin{tabular}{|c|c|c|c|c|c|c|}
\hline Kriter & Gecikme & Paket Kayb1 & Seğirme & Maliyet & TBG & KBG \\
\hline Gecikme & EÖ & YÖ & EÖ & AÖ & AÖ & EÖ \\
\hline Paket Kayb1 & TYÖ & EÖ & TYÖ & AÖ & YÖ \\
\hline Seğirme & EÖ & YÖ & EÖ & EÖ & TAÖ & AÖ \\
\hline Maliyet & TAÖ & TAÖ & TAÖ & TAÖ & EÖ & TAÖ \\
\hline TBG & TYÖ & EÖ & TYÖ & AÖ & AÖ & EÖ \\
\hline KBG & TYÖ & AÖ & TAÖ & \multicolumn{2}{c|}{ AÖ } \\
\hline
\end{tabular}

Aday ağlardan elde edilen parametrelerin değerleri Tablo 3 'te gösterilmektedir.

Durulaştırılmış çift yönlü karşılaştırma matrisinin tutarlılık kontrolü DTraT yöntemi kullanılarak elde edilmiştir ve
Tablo 4' de verilmiştir. Kriterler için tutarlılık oranının kabul edilebilir düzeyde olduğu belirlenmiştir.

Ardından adım 3'e göre çift yönlü karşılaştırma matrisinde her satırın geometrik ortalaması hesaplanır. Hesaplama 
işlemi için 4 no'lu eşitlikteki formül aşağıdaki gibi kullanilır.

$$
\tilde{\tilde{r}}_{1}=\left[\tilde{\tilde{a}}_{11} \otimes \tilde{\tilde{a}}_{12} \otimes \tilde{\tilde{a}}_{13} \otimes \tilde{\tilde{a}}_{14} \otimes \tilde{\tilde{a}}_{15} \otimes \tilde{\tilde{a}}_{16}\right]^{\frac{1}{6}}
$$

Geometrik ortalama hesaplandıktan sonra oluşan değerler Tablo 5'te gösterilmektedir. Adım 5'e göre kriterlerin öncelikli ağırlıkları Tablo 5'teki geometrik ortalama değerleri kullanılarak 5 no'lu eşitliğe göre hesaplanmıştır. Hesaplanan değerler Tablo 6'da gösterilmekte ve bu değerler durulaştırılıp ardından normalize edilmiştir. Her bir kriter için oluşturulan değerler sırasıyla $(0.30,0.08$, $0.30,0.07,0.08,0.15)$ şeklindedir ve Şekil 3 'te gösterilmektedir.

Normalize edilen bu değerler, alternatiflere ait parametreler (Tablo 7) ile çarpılır. Çarpım sonucunda oluşan değerler Tablo 8'de gösterilmektedir. $\mathrm{Bu}$ değerlerden ağırlıklandırılmış toplam değerler Tablo 9'daki gibi oluşturulur.

Tablo 3: Aday ağlardan elde edilen parametreler. (Parameters obtained from candidate networks)

\begin{tabular}{|c|c|c|c|c|c|c|}
\hline & G & PK & S & M & TBG & KBG \\
\hline AĞ1 & 119,8 & 0,075 & 7,15 & 0,12 & 7,2 & 2,828 \\
\hline AĞ2 & 48,85 & 0,0102 & 0,25 & 0,09 & 8 & 0,656 \\
\hline AĞ3 & 42,95 & 0,013 & 0,21 & 0,12 & 20 & 0,835 \\
\hline AĞ4 & 52,2 & 1,292 & 1,45 & 0,04 & 3 & 0,475 \\
\hline AĞ5 & 49,95 & 0,0106 & 7,68 & 0,02 & 1 & 0,888 \\
\hline
\end{tabular}

Tablo 4: Kriterler için durulaştırılmış ikili matris.

\begin{tabular}{|c|c|c|c|c|c|c|}
\hline & G & PK & S & M & TBG & KBG \\
\hline G & 1 & 4,75 & 1 & 2,87 & 4,75 & 2,85 \\
\hline PK & 0,21 & 1 & 0,21 & 2,87 & 1 & 0,44 \\
\hline S & 1 & 4,75 & 1 & 2,87 & 4,75 & 2,85 \\
\hline M & 0,44 & 0,44 & 0,44 & 1 & 0,45 & 0,44 \\
\hline TBG & 0,21 & 1 & 0,21 & 2,87 & 1 & 0,44 \\
\hline KBG & 0,21 & 2,85 & 0,44 & 2,87 & 2,85 & 1 \\
\hline
\end{tabular}

Ağırlıklandırılmış toplam değerler uygulanan aralık Tip-2 bulanık AHS yöntemi sonucunda alternatiflerin sıralamalarının elde edilmesini sağlar. Alternatiflerin değerleri büyükten küçüğe doğru sıralanır. Değerler arasında en büyük olan seçimde ilk sırada yer alır.
Tablo 5: Kriterler için ikili karşılaştırma matrisinin geometrik ortalamasi.

(The geometric mean of the pairwise comparison matrix for criteria)

\begin{tabular}{|c|c|}
\hline Kriter & Geometrik Ortalama \\
\hline G & $(1.4,2,2.88 .3,27,1,1)(1.56,2.09,2.80,3.19,0.8,0.8)$ \\
\hline PK & $(0.39,0.49,0.7,0.90,1,1)(0.41,0.5,0.67,0.85,0.8,08)$ \\
\hline S & $(1.44,2,2.8,3.2,1,1)(1.5,2.09,2.8,3.1,0.8,0.8)$ \\
\hline M & $(0.2,0.3,0.56,1,1,1)(0.27,0.3,0.5,0.67,0.85,0.8,0.8)$ \\
\hline TBG & $(0.39,0.49,0.7,0.9,1,1)(0.41,0.5,0.6,0.85,0.8,0.8)$ \\
\hline KBG & $(0.5,0.8,1.41,1.86,1,1)(0.6,0.88,1.3,1.7,0.8,0.8)$ \\
\hline
\end{tabular}

Tablo 6: Kriterlerin öncelikli ağırlıkları. (Priority weights of the criteria)

\begin{tabular}{|c|c|}
\hline & (Priority weights of the criteria) \\
\hline G & $(0.12,0.21,0.47,0.72,1,1)(0.14,0.23,0.43,0.65,0.8,0.8)$ \\
\hline PK & $(0.03,0.05,0.11,0.20,1,1)(0.03,0.05,0.10 .0 .17,0.8,0.8)$ \\
\hline S & $(0.12,0.21,0.47,0.72,1,1)(0.14,0.23,0.43,0.65,0.8,0.8)$ \\
\hline M & $(0.02,0.03,0.09,0.22,1,1)(0.02,0.03,0.08,0.17,0.8,0.8)$ \\
\hline TBG & $(0.03,0.05,0.11,0.20,1,1)(0.03,0.05,0.10,0.17,0.8,0.8)$ \\
\hline KBG & $(0.04,0.09,0.23,0.41,1,1)(0.05,0.1,0.20,0.36,0.8,0.8)$ \\
\hline
\end{tabular}

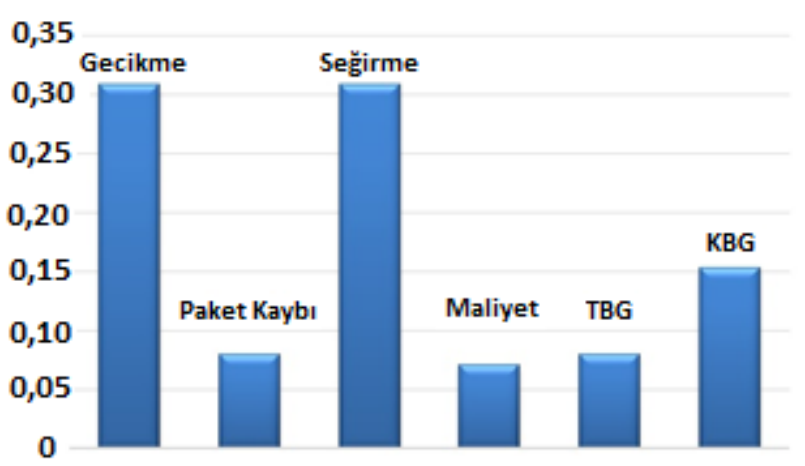

Şekil 3: Kriterlerin Normalleştirilmiş Ağırlıkları (Normalized Weights of Criteria)

Hesaplamaların sonucunda heterojen bilgisayar ağları seçiminde en iyi alternatifin "AĞ3”, en kötü alternatifin ise "AĞ1" alternatifi olduğu elde edilmiştir. Sıralama ise

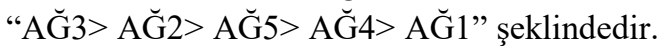


Tablo 7: Parametrelere ait bulanık değerler.

\begin{tabular}{|c|c|c|c|c|c|c|}
\hline & G & $\mathrm{PK}$ & $\mathrm{S}$ & M & TPC & $F D C$ \\
\hline AĞ1 & 0.525 & 0.825 & 0.48 & 0.254 & 0.482 & 0.85 \\
\hline AĞ2 & 0.757 & 0.825 & 0.855 & 0.449 & 0.5 & 0.383 \\
\hline AĞ3 & 0.814 & 0.825 & 0.855 & 0.254 & 0.837 & 0.449 \\
\hline AĞ4 & 0.73 & 0.15 & 0.715 & 0.682 & 0.294 & 0.27 \\
\hline AĞ5 & 0.74 & 0.825 & 0.48 & 0.851 & 0.12 & 0.47 \\
\hline
\end{tabular}

Tablo 8: Kriter ve alternatif değerlerinin çarpımı. (Product of criterion and alternative values)

\begin{tabular}{|c|c|c|c|c|c|c|}
\hline & $\mathrm{G}$ & $\mathrm{PK}$ & $\mathrm{S}$ & $\mathrm{M}$ & $\mathrm{TBG}$ & $\mathrm{KBG}$ \\
\hline AĞ 1 & 0.161 & 0.066 & 0.147 & 0.017 & 0.038 & 0.130 \\
\hline AĞ2 & 0.233 & 0.066 & 0.313 & 0.031 & 0.040 & 0.058 \\
\hline AĞ3 & 0.250 & 0.066 & 0.313 & 0.017 & 0.067 & 0.068 \\
\hline AĞ4 & 0.224 & 0.012 & 0.261 & 0.048 & 0.023 & 0.041 \\
\hline AĞ5 & 0.230 & 0.066 & 0.175 & 0.060 & 0.009 & 0.072 \\
\hline
\end{tabular}

Tablo 9: Alternatiflerin seçimi. (Selection of alternatives.

\begin{tabular}{|c|c|}
\hline Alternatifler & $\begin{array}{c}\text { Alternatiflerin } \\
\text { Ağırlıklandırılmış Toplam } \\
\text { Değeri }\end{array}$ \\
\hline AĞ1 & 0.562 \\
\hline AĞ2 & 0.742 \\
\hline AĞ3 & 0.783 \\
\hline AĞ4 & 0.611 \\
\hline AĞ5 & 0.613 \\
\hline
\end{tabular}

3.2. Aralık tip-2 bulanı TOPSIS yöntemi ile değerlendirme (Evaluation with Interval Type-2 Fuzzy TOPSIS method)

Aralık Tip-2 TOPSIS yönteminde de Tablo 1'deki dilsel değerler kullanılmıştır. Tablo 10'daki değerler, Tüker'in çalışmasındaki [12] aday ağlardan alınan parametrelerin bulanıklaştırılmasından sonra, bu değerlere karşılık gelen dilsel değerler ile oluşturulmuştur. Tablo 10 baz alındığında eşitlik 7 kullanılarak karar matrisi oluşturulur. Ardından değerlerinden ortalama karar matrisi oluşturulur. İlk üç değer aşağıdaki gibidir:

$$
\begin{aligned}
& \tilde{\tilde{f}}_{11}=((0.5,0.6,0.8,0.9,1,1),(0.52,0.6,0.8,0.9,0.8,0.8)) \\
& \tilde{\tilde{f}}_{12}=((0.1,0.2,0.4,0.5,1,1),(0.12,0.2,0.4,0.5,0.8,0.8)) \\
& \tilde{\tilde{f}}_{13}=((0.1,0.2,0.4,0.5,1,1),(0.12,0.2,0.4,0.5,0.8,0.8))
\end{aligned}
$$

Tablo 10: Alternatiflerin farklı kritere göre değerlendirilmesi.

(Evaluation of alternatives according to different criteria)

\begin{tabular}{|c|c|c|c|c|c|c|}
\hline & Gecikme & Paket Kayb1 & Seğirme & Maliyet & TBG & KBG \\
\hline AĞ1 & ÇÖ & AÖ & YÖ & ÇÖ & YÖ & MÖ \\
\hline A $\breve{2} 2$ & AÖ & EÖ & EÖ & YÖ & YÖ & AÖ \\
\hline AĞ3 & AÖ & EÖ & EÖ & ÇÖ & MÖ & YÖ \\
\hline AĞ4 & AÖ & MÖ & AÖ & AÖ & AÖ & AÖ \\
\hline AĞ5 & AÖ & EÖ & ÇÖ & EÖ & EÖ & YÖ \\
\hline
\end{tabular}

Tablo 11: Karar verici değerlendirme ağırlıkları. (Displaying of the connections between nodes)

\begin{tabular}{|c|c|}
\hline Kriterler & Karar Verici \\
\hline $\mathrm{G}$ & AÖ \\
\hline PK & ÇÖ \\
\hline $\mathrm{S}$ & AÖ \\
\hline $\mathrm{M}$ & YÖ \\
\hline TBG & MÖ \\
\hline KBG & ÇÖ \\
\hline
\end{tabular}

Karar verici olarak değerlendirilen kriterlerin ağırlıkları Tablo 11'de gösterilmektedir. Karar verici değerlerine göre eşitlik 9 kullanılarak ağırlık matrisi oluşturulur. Eşitlik 10 ve 11 ile ortalama ağırlık matrisi hesaplanır. 12 no'lu eşitlik kullanılarak ağırlıklı karar matrisi $\bar{Y}_{w}$ oluşturulur.

Sıralı ağırlıklandırılmış karar matrisi (Rank) değerleri hesaplanır ve eşitlik 13 temel alınarak sonuçlar aşağıdaki gibi hesaplanır:

$$
\bar{Y}_{w}^{*}=\begin{gathered}
G \\
P K \\
S \\
M \\
T B G \\
K B G
\end{gathered}\left[\begin{array}{ccccc}
4,47 & 3,82 & 3,82 & 3.82 & 3.82 \\
4.47 & 4.00 & 4.00 & 6.64 & 4.00 \\
4.14 & 3.76 & 3.76 & 3.82 & 4.47 \\
5.28 & 4.71 & 5.28 & 4.14 & 3.88 \\
5.65 & 5.65 & 7.35 & 4.67 & 4.09 \\
6.64 & 4.47 & 5.28 & 4.47 & 5.28
\end{array}\right]
$$


Sıralı ağırlıklandırılmış karar matrisinden faydalanarak eşitlik 14 ve 15 ile birlikte pozitif ve negatif ideal çözüm bulunur. Pozitif ve negatif ideal çözüm Tablo 12'de verilmiştir.

Tablo 12: Kriterler için durulaştırılmış ikili matris.

\begin{tabular}{|c|c|c|}
\hline \multicolumn{2}{|c|}{ (Defuzzified pairwise matrix for criteria) } \\
\hline Kriter & Pozitif İdeal & Negatif Ideal \\
\hline G & 4.47 & 3.82 \\
\hline PK & 6.64 & 4.00 \\
\hline S & 4.47 & 3.76 \\
\hline M & 5.28 & 3.88 \\
\hline TBG & 7.35 & 4.09 \\
\hline KBG & 6.64 & 4.47 \\
\hline
\end{tabular}

Her alternatifin pozitif ve negatif ideal çözüme olan uzaklıklarını bulmak için 16 ve 17 no'lu eşitlikler kullanılır. Sonuçlar Tablo 13'te gösterilmektedir.

Pozitif ideal çözüme ve negatif ideal çözüme olan uzaklıklar kullanılarak eşitlik 18 yardımı ile yakınlık katsayıları hesaplanır. Değerler hesaplandıktan sonra büyükten küçüğe doğru sıralama yapılır. Sıralama sonucu Tablo 14'de gösterilmektedir.

Tablo 13: Pozitif ve negatif ideal çözüm arasındaki mesafe. (The distance between positive and negative ideal solution)

\begin{tabular}{|c|c|c|c|c|c|}
\hline & AĞ1 & AĞ2 & AĞ3 & AĞ4 & AĞ5 \\
\hline$d^{+}$ & 2.77 & 3.97 & 3.12 & 3.74 & 4.67 \\
& & & & & \\
\hline$d^{-}$ & 3.14 & 1.77 & 3.63 & 2.71 & 1.07 \\
\hline
\end{tabular}

Tablo 14: Yakınlık katsayıları ve sıralama.

\begin{tabular}{|c|c|c|c|c|c|}
\hline & Ă̆1 & AĞ2 & AĞ3 & AĞ4 & AĞ5 \\
\hline Yakınlık Katsayısı & 0.531 & 0.308 & 0.538 & 0.420 & 0.187 \\
\hline Siralama & 2 & 4 & 1 & 3 & 5 \\
\hline
\end{tabular}

En yüksek değere sahip AĞ1 alternatifi, aralık tip-2 TOPSIS metoduna göre ilk sirada yer almaktadır. Tercih

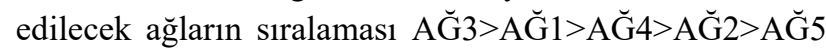
şeklindedir.
3.3. İki Yöntemin Karşılaştırılması (Comparison of Two Methods)

Aralı Tip-2 Bulanık AHS ve Aralık Tip-2 Bulanık TOPSIS yöntemlerinden elde edilen sonuçlar Tablo 15 'te verilmiştir.

Tablo 15: İki yöntemin karşılaştırılması. (Comparison of the two methods)

\begin{tabular}{|l|c|c|}
\hline \multicolumn{1}{|c|}{ Siralama } & AHS & TOPSIS \\
\hline AĞ1: 3G & 5 & 2 \\
\hline AĞ2: ADSL & 2 & 4 \\
\hline A $\breve{G} 3:$ FiBER İNTERNET & 1 & 1 \\
\hline AĞ4: KABLONET & 4 & 3 \\
\hline AĞ5: PLC & 3 & 5 \\
\hline
\end{tabular}

Tablo 15'de yer alan sonuçlara göre ağ seçiminde her iki yöntemde de ilk sırada fiber internet yer almaktadır. İlk yöntem olan aralık tip-2 AHS'ye göre fiber internetten sonra bunu takip eden diğer alternatifler ağ 2-5-4-1 şeklindedir. Aralık tip-2 TOPSIS yöntemine göre de ilk alternatiften sonra diğer yöntemden farklı olarak alternatiflerin sıralaması ardı ardına 1-4-2-5 şeklindedir. İki yöntem sonucunda da alternatiflerin tercihinde ilk sırada fiber internet teknolojisinin yer alması sonuçların birbirlerini desteklediğini ortaya koymaktadır. Aday ağların grafiksel gösterimi Şekil 4'de yer almaktadır.

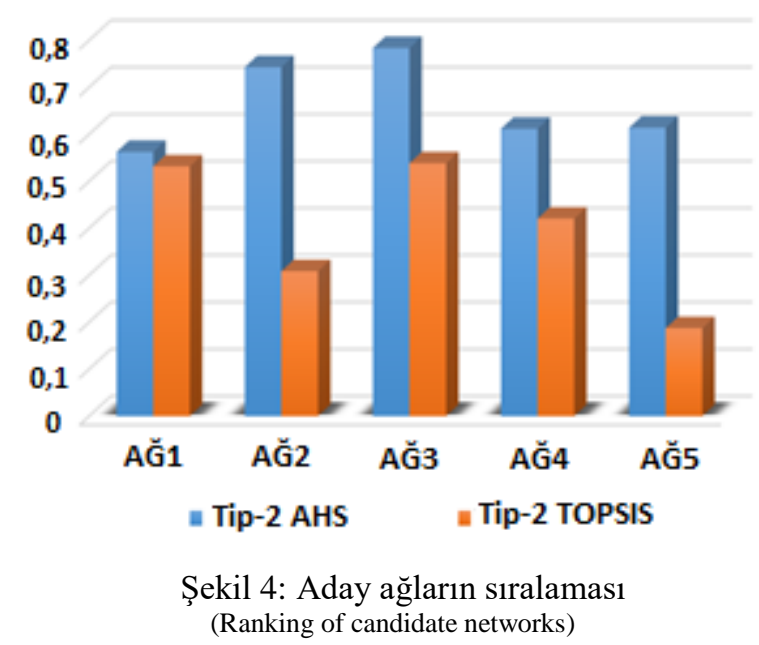

Başlangıçta aday ağlardan elde edilen parametrelere göre kriterler ele alındığında, AĞ3'ün değerlerinin diğer alternatiflere göre düşük olması AĞ3 alternatifini üstün kılmaktadır. Kriter ağırlıkları incelendiğinde fiber internetin diğer kablolu bağlantı türlerine göre gecikme ve seğirme değerlerinin düşük olması ve kullanılabilir bant 
genişliğinde yüksek değere sahip olması sıralama sonuçlarına olumlu olarak yansımıştır.

Uygulanan yöntemler, kriterler ile birlikte değerlendirildiğinde Tip-2 bulanık kümelerin kullanılması, Tip-1 bulanık kümelere kıyasla fazladan bir boyut daha olduğu için kesin değil aralıklı üyelik değerleri kullanılmasını sağlayarak alternatifler arasındaki farkları daha net ortaya çıkarmaktadır. Tip-2 bulanık kümeler kullanılarak uygulanan AHS ve TOPSIS yöntemlerinin sonuçları doğrultusunda AHS yöntemi Tüker [12] çalışmasındaki sıralamayı vermiş ve alternatiflerin daha net ayrışmasını sağlamıştır.

\section{SONUÇ (CONCLUSION)}

Kullanıcıların bilgi eksikliğinden dolayı ağ seçiminde doğru tercihler yapması pek mümkün değildir. Her ağın kendine özel özellikleri ve belirli kriterleri göz önüne alındığında ve tüm ağların var olarak kabul edildiği bir ortamda kullanıcıların ihtiyaçlarına göre en verimli ağ hizmetini kullanması karmaşık bir problemdir. Böyle bir problem için tek kriter ile çözüm aramak yetersizdir. $\mathrm{Bu}$ nedenle problemde kullanıcıya en iyi hizmeti veren ağın seçimi çok fazla kriter ile değerlendirileceğinden büyük oranda belirsizlik içermektedir.

Heterojen bilgisayar ağları seçimi hakkında yapılan bu çalışmada altı kriter ve beş farklı alternatiften oluşan hiyerarşik bir model kurulmuştur. Problem bulanık mantık kapsamında değerlendirildiğinde belirsizliğin tam olarak modellenebilmesi için Tip-1 yerine aralık Tip-2 bulanık kümeler tercih edilmiştir. Bu bağlamda değerlendirmeler iki farklı yöntem ile yapılmış ve elde edilen sonuçlar karşılaştırılmıştır. Yöntemler ile birlikte Tip-2 bulanık kümelerin kullanılması hassaslığı arttırarak alternatiflerin daha iyi ayrışmasını sağlamıştır. Karar verici tercihlerine ve amaca göre sonuçlar değişkenlik göstermektedir.

Bu çalışmada sabit kullanıcılar için heterojen kablolu ve kablosuz ağlar ele alınmıştır. Literatürde heterojen ev ağları seçimi için, aralık Tip-2 bulanık kümelere ilişkin model kurulmuş bir örnek bulunmamaktadır. Bu nedenle Tip-2 bulanık kümeler ile kullanılan yöntemler, uygulanan konu bazında daha hassas sonuçlar ortaya çıkardığı için gelecekte yapılabilecek çalışmaların değerlendirilmesinde yol gösterici niteliğindedir.

\section{KAYNAKLAR (REFERENCES)}

[1] F. Bari, V. Leung, "Automated Network Selection in a Heterogeneous Wireless Network Environment", IEEE Network, 21(1), 34-40, 2007.
[2] S. Ballı, Fuzzy çok kriterli karar verme ve basketbolda oyuncu seçimine uygulaması, Yüksek Lisans Tezi, Muğla Sıtkı Koçman Üniversitesi, Fen Bilimleri Enstitüsü, 2005.

[3] M. Eminov, S. Ballı, "Karmaşık problemler için belirsizlik altinda çok kriterli bulanik karar verme". Yöneylem Araştırması/Endüstri Mühendisliği-XXIV. Ulusal Kongresi, Adana, Türkiye, 15-18, 2004.

[4] S. Ballı, Melez Zeki Karar Destek Sistemlerinin Tasarımı ve Gerçekleştirimi. Doktora Tezi, Ege Üniversitesi, Fen Bilimleri Enstitüsü, 2010

[5] Y. Bai., Z.S. Roth. Classical and Modern Controls with Microcontrollers: Design, Implementation and Applications, Springer, Cham, Switzerland 2019.

[6] M. Öztürk, T. Paksoy, M. Öztürk, “Aralık Tip-2 Bulanık Mantık Yönteminin Tedarikçi Seçiminde Kullanımının Önemi Üzerine Bir Araştırma". Türkiye Bilişim Vakfi Bilgisayar Bilimleri ve Mühendisliği Dergisi, 10(2), 1-18, 2017.

[7] H.J. Wang, R.H. Katz, J. Giese, "Policy-Enabled Handoffs Across Heterogeneous Wireless Networks", Proceedings of IEEE Mobile Computing Systems and Applications, 51-60, 1999.

[8] E. Alexandri, G. Martinez, D. Zeghlache, "Adaptive Joint Call Admission Control and Access Network Selection for Multimedia Wireless Systems", Proceedings of 5th International Symposium on Wireless Personal Multimedia Communications, Hawaii, ABD, 27-30 October, 2002.

[9] L. Wang, D. Binet. "MADM-based Network Selection in Heterogeneous Wireless Networks: A Simulation Study", 1st International Conference on Wireless Communication, Vehicular Technology, Information Theory and Aerospace \& Electronic Systems Technology, Aalborg, Denmark, 17-20 May, 2009.

[10] A.T. Macriga, A.P. Kumar, "Mobility Management for Seamless Flow of Information in Wireless Networks", European Journal of Scientific Research, 52(2), 147-155, 2011.

[11] P. TalebiFard, V.C.M. Leung. "A Dynamic Context-Aware Access Network Selection for Handover in Heterogeneous Network Environments", IEEE Conference on Computer Communications Workshops, Shanghai, China, 10-15 April, 2011.

[12] M. Tüker, Heterojen bilgisayar ağları için zeki seçim sistemleri geliştirilmesi. Yüksek Lisans Tezi, Muğla Sıtkı Koçman Üniversitesi, Fen Bilimleri Enstitüsü, 2013.

[13] D. Koçak, Y.E. Çoğurcu, "Network Modeli İle Ağ Analizi İçin Çok Kriterli Karar Verme Yöntemleriyle Karşılaştırmalı Çözüm”, Gazi İktisat ve İşletme Dergisi,1(1), 1-42, 2015.

[14] M. Drissi, M. Oumsis, D. Aboutajdine "A fuzzy ahp approach to network selection improvement in heterogeneous wireless networks", International Conference on Networked Systems, Cham, May 2016.

[15] V. Sasirekha, C. Chandrasekar, M. Ilangkumaran, "Heterogeneous wireless network vertical handoff decision using hybrid multicriteria decision-making technique", International Journal of Computational Science and Engineering, 10(3), 263-280, 2015. 
[16] S. Kunarak, R. Sulessathira, "Multi-criteria Vertical Handoff Decision Algorithm for Overlaid Heterogeneous Mobile IP Networks", Journal of the Franklin Institute, 357(10), 6321-6351, 2020 .

[17] K. Kumar, M. S. Gupta. Smart Computational Strategies: Theoretical and Practical Aspects. Springer, Singapore. 2019.

[18] S. Qutub, T. Anjali, "Network Assisted Network Selection.”, IEEE 2012 International Conference on Electro/Information Technology, Indianapolis, ABD, 6-8 May 2012.

[19] S. Ballı, M. Tüker, "A Fuzzy Multi-Criteria Decision Analysis Approach for the Evaluation of the Network Service Providers in Turkey", Intelligent Automation \& Soft Computing, 24(4), 693 699, 2018.

[20] İnternet: Bilgi Teknolojileri ve İletişim Kurumu, Pazar Verileri, https://www.btk.gov.tr/pazar-verileri, 03.03.2020.

[21] J.A.C. Bingham. ADSL VDSL and multicarrier Modulation Wiley, New York, A.B.D., 2000.

[22] A.S. Tanenbaum. Computer networks. Prentice Hall, New Jersey, A.B.D., 2003.

[23] İnternet: F. Işıdoğan, Powerline Communication http://www.isikdogan.com/turkce-blog/powerlinecommunication.html, 03.03.2020.

[24] Z. YanHua, M. WeiZhe, "The Design of Cable Television IP Access Network Based on Hot Standby Router Protocol", International Conference on Image Analysis and Signal Processing, Hangzhou, China, 9-11 Nov, 2012.
[25] W. Lehr, L.W. McKnight, "Wireless internet access: 3G vs. WiFi?”, Telecommunications Policy, 27(5-6), 351-370, 2003.

[26] B.A. Forouzan. Data communications and networking. McGraw-Hill Education, New York, A.B.D., 2007.

[27] R.L. Carter, M.E. Crovella, "Measuring bottleneck link speed in packet-switched networks", Performance Evaluation, 27(4), 297 318, 1996.

[28] J. J. Buckley, "Fuzzy hierarchical analysis", Fuzzy sets and systems, 17(3), 233-247, 1985.

[29] C. Kahraman, B. Öztayşi, İ.U. Sarı, E. Turanoğlu, "Fuzzy analytic hierarchy process with interval type-2 fuzzy sets", KnowledgeBased Systems, 59, 48-57, 2014.

[30] C. Kahraman, S. Cevik, B. Oztaysi, "Fuzzy Multicriteria DecisionMaking: A Literature Review", International Journal of Computational Intelligence Systems, 8(4), 637-666, 2015.

[31] S. Balli, M. Yilmaz, "Multi-criteria usability evaluation of symmetric data encryption algorithms in fuzzy environment", $S N$ Applied Sciences, 2(8), 1393, 2020.

[32] S.M. Chen, L.W. Lee, "Fuzzy multiple attributes group decisionmaking based on the interval type-2 TOPSIS method", Expert Systems with Applications, 37(4), 2790-2798, 2010.

[33] S. Ballı, B. Karasulu, A. Uğur, S. Korukoğlu, "Basketbolda oyuncu seçimi için sinirsel-bulanık karar destek sistemi”, ITÜ Dergisi/d Mühendislik, 8(1), 15-25, 2009. 